\title{
Implante de traquéia de Gallus domesticusna microanastomose arterial em cães
}

\author{
Tracheal graft of Gallus domesticus in canine arterial microanastomosis
}

\author{
Emerson Antonio Contesini ${ }^{1}$, Ney Luis Pippi ${ }^{2}$, Carlos Afonso de Castro Beck ${ }^{1}$, \\ Maurício Veloso Brun ${ }^{3}$, Carmen Lice Buckman de Godoy², Dominguita Lühers Graça², \\ Antônio de Pádua Ferreira da Silva Filho ${ }^{1}$, Adamas Tassinari Bonfada², Rafael Stedile ${ }^{1}$, \\ Lucas Marques Colomé ${ }^{1}$, Kleber Gomes ${ }^{2} \&$ Fabrício de Vargas Arigony Braga $^{2}$
}

\begin{abstract}
RESUMO
Os animais são pouco sujeitos a distúrbios vasculares primários, porém todas as lesões envolvem trauma vascular e são representadas por hemorragias mais ou menos intensas. Em geral as lesões de vasos sangüíneos maiores podem ser reparadas por sutura direta, por anastomose ou por implantes de condutos prostéticos. Este trabalho teve como objetivo testar a traquéia de Gallus domesticus na substituição de um segmento da artéria femoral em cães. Para isso, foram utilizados 16 cães adultos, sem raça definida, hígidos, de ambos os sexos. Nas anastomoses microcirúrgicas foram utilizados fios sintéticos inabsorvíveis de polipropileno, com pontos simples interrompidos. O sucesso cirúrgico foi avaliado pela verificação da patência dos vasos nos vinte minutos após o término da anastomose por teste de patência e também aos 60 ou 120 dias pós-operatórios. A traquéia de Gallus domesticus pode ser utilizada como substitutivo segmentar da artéria femoral em cães, independende do meio de conservação, porém a manutenção da patência está estatisticamente relacionada com o tempo de observação do implante.
\end{abstract}

Descritores: implante traqueal, microcirurgia, cirurgia vascular

\begin{abstract}
Animals are little assailed by primary vascular disturbs, but all the lesions involve vascular trauma and intense or weak hemorrhage. In general lesions of big sanguineous vessels can be repaired by direct suture by anastomosis or artificial grafts. The aim of this study was to test Gallus domesticus trachea in substitution of canine femoral artery segment. For such, 16 adult dogs without defined race, healthy, of both the sexes were used. Synthetic wires of unabsorbing polypropylene were used in microsurgical anastomosis, with interrupt suture pattern. The surgical success was evaluated through the vessel patency verification in the first 20 minutes after the conclusion of anastomosis by patency test and in the 60 or 120 postoperative days it was evaluated through contrast angiography. The Gallus domesticus trachea can be used like segmentary substitute of femoral artery in dogs, independent of its conservation medium, however the patency maintenance is linked with observation time, in accord the statistical analysis.
\end{abstract}

Key words: tracheal graft, microsurgery, vascular surgery. 


\section{INTRODUÇÃO}

Com a evolução da microcirurgia vascular e sua implantação na rotina da Medicina Veterinária, houve um aumento de casos de implantação de próteses e conseqüentemente da incidência de complicações [18].

Diversos materiais sintéticos ou biológicos conservados têm sido utilizados como implantes, tanto para reaproximar extremidades vasculares danificadas como para substituir segmentos degenerados. O sucesso na implantação de próteses microvasculares deve-se não apenas a suas propriedades trombogênicas, mas ao processo de reparação durante sua incorporação e, possivelmente, à diferenciação de suas paredes. Algumas alternativas foram testadas ao longo dos últimos anos, com resultados heterogêneos, dependendo do material e da pesquisa realizada [28].

Os fios mais indicados para anastomose vascular são os sintéticos inabsorvíveis, como o mononáilon [26] e o polipropileno [11,25]. O fio polipropileno monofilamentar é o mais freqüentemente utilizado em cirurgias vasculares, pois, além de macio, resistente e inerte, o fio perde pouco da sua força com o decorrer do tempo, depois de implantado e sua cor azul permite ótima visibilidade trasnsoperatória [29].

Este trabalho teve como objetivo avaliar macro e microscopicamente a qualidade cicatricial da microanastomose da artéria femoral, utilizando-se fio polipropileno frente ao implante de traquéia de Gallus domesticus conservado em glicerina a $98 \%$ ou em solução concentrada de cloreto de sódio, assim como a manutenção da patência aos 60 e 120 dias pós operatório.

\section{MATERIAIS E MÉTODOS}

Para este experimento foram utilizados 16 animais da espécie canina, sem raça definida, machos e fêmeas, adultos hígidos, com peso médio de 15,0kg. Todos os animais tiveram um segmento da artéria femoral substituído por um implante de traquéia de Gallus domesticus, separados em dois grupos. O primeiro grupo (G1) constituído por 8 animais, para implantação do biomaterial conservado em solução de glicerina a $98 \%$, enquanto o segundo grupo (G2) também constituído por 8 animais, o biomaterial foi conservado em solução concentrada de cloreto de sódio.
O fio de sutura utilizado para ambos os grupos foi polipropileno (8-0) com tempo de observação de 60 e 120 dias para cada metade de grupo. O acompanhamento das variáveis ocorreu de modo independente.

Um dia antes da cirurgia, os implantes foram removidos do meio conservante, lavados com solução salina isotônica e submersos em solução de polivinilpirrolidona (PVP-I) diluída numa proporção de 1:50 em solução de $\mathrm{NaCl}$ 0,9\%, sendo lavado imediatamente antes da cirurgia, o material foi lavado com solução salina isotônica. Na seqüência, os implantes foram transferidos para cuba em meio de solução heparinizada, na proporção de $10 \mathrm{UI} . \mathrm{mL}^{-1} \mathrm{de}$ solução de Ringer.

O protocolo anestésico constou de maleato de acepromazina $\left(0,1 \mathrm{mg} \cdot \mathrm{kg}^{-1}\right)$, por via intravenosa (IV), e citrato de fentanila $\left(0,005 \mathrm{mg} \cdot \mathrm{kg}^{-1} \mathrm{IV}\right)$. A indução à anestesia geral deu-se através de tiopental sódico $\left(12,5 \mathrm{mg} \cdot \mathrm{kg}^{-1} \mathrm{IV}\right)$ e a manutenção foi realizada com isoflurano vaporizado em oxigênio a 100\%, em circuito semifechado, com respiração mecanicamente controlada. Imediatamente antes à cirurgia, foi administrado antibiótico profilático a base de ampicilina sódica (20mg.kg-1 IV).

O acesso cirúrgico foi longitudinal, a partir da almofada adiposa epigástrica, até a bifurcação da artéria femoral. Depois de inseridos dois clipes vasculares de Kleinert-Kurtz na artéria femoral, distantes $4 \mathrm{~cm}$ um do outro, instilou-se algumas gotas de lidocaína a $1 \%$ em toda extensão exposta do vaso, para prevenir espasmos. A partir daí, foi utilizado microscópio cirúrgico com magnificação de 10x.

A artéria sofreu secção transversal num ponto eqüidistante dos dois clipes. O sangue remanescente na luz do vaso, extraído com solução salina com heparina (10UI.mL $\left.{ }^{-1}\right)$, injetada sob pressão moderada com auxílio de seringa e de agulha hipodérmica $13 \mathrm{x}$ 0,45 . Uma vez removido o sangue do campo operatório e do lume do vaso, retirou-se a camada adventícia das extremidades vasculares, com movimentos semelhantes aos de uma circuncisão.

A microanastomose foi iniciada a partir de dois pontos de reparo na extremidade proximal da artéria, junto ao implante, dispostos em $180^{\circ}$. Esses pontos foram tracionados látero-verticalmente e o intervalo entre eles, preenchidos com pontos simples interrompidos com polipropileno 8-0. Posteriormente promoveu-se a rotação do conjunto artéria-implante em $180^{\circ}$, 
tracionados novamente os pontos de reparo e concluída a anastomose. Ao final da anastomose, o clipe distal foi removido, permitindo o preenchimento da artéria e do implante pelo refluxo sangüíneo. Em seguida, removeuse o clipe proximal.

Para certificar a patência vascular foi observado o fluxo sangüíneo com os sinais de permeabilidade local, aplicando-se teste de patência por um período de aproximadamente 20 minutos.

No final da cirurgia e nos dois dias subseqüentes, os animais receberam flunixin meglumine, na dose de $1,0 \mathrm{mg} \cdot \mathrm{kg}^{-1} \mathrm{IV}$.

O pós operatório foi constituído por curativo local com solução de clorexidine a $4 \%$ durante sete dias, ao final do qual foram removidos os pontos de sutura.

Para a angiografia contrastada, realizada aos 60 ou aos 120 dias, imediatamente antes da biópsia, os animais foram novamente submetidos a anestesia geral, com o mesmo protocolo anestésico anterior. A artéria ilíaca externa correspondente ao lado do implante foi cateterizada com sonda descartável siliconizada. Utilizou-se meio de contraste composto por amidotrizoato sódico e amidotrizoato de meglumina a $76 \%$.

As amostras foram seccionadas longitudinalmente para observação da luz vascular e para avaliação do endotélio e posteriormente acondicionadas em meio de formol tamponado, emblocadas, com inclusão em parafina. Os implantes foram retirados e fixados em formol a 10\%, incluídos em parafina, cortados longitudinalmente em 5 micrômetros de espessura e colados pela técnica de Hematoxilina -Eosina. Os cortes foram examinados em microscópio óptico.

A qualidade anti-séptica dos meios conservantes foi avaliada, durante o período de uso dos implantes, a partir de amostras dos meios em que esses foram submersos. A pesquisa microbiológica foi realizada com cultivo em Ágar Sangue a $37^{\circ} \mathrm{C}$ por 24 horas.

\section{RESULTADOS}

A solução de heparina diluída em Ringer, permitiu a remoção dos coágulos presentes nos cotos arteriais, assim como preveniu a sua formação após o término da anastomose. Não houve sangramento persistente e constatou-se presença de pulso na porção distal ao implante em teste realizado até 20 minutos após o término da anastomose. O espasmo vascular foi prevenido com aplicação tópica de lidocaína a $1 \%$ imediatamente antes da secção da artéria.

Os meios de conservação utilizados, solução concentrada de sal e solução de glicerina a $98 \%$, revelaram-se eficientes, já que o líquido, na avaliação macroscópica, permaneceu durante todo o experimento com o mesmo aspecto do início da fase de conservação. $\mathrm{O}$ implante, por sua vez, manteve a mesma forma estrutural, alterando-se tão somente sua consistência, mais amolecido quando conservado em solução saturada de cloreto de sódio e mais rígida na glicerina a 98\%. Na análise microbiológica, diante do protocolo empregado em Ágar Sangue $\left(37^{\circ} \mathrm{C} / 24 \mathrm{~h}\right)$ para avaliação do meio de conservação, não foram observadas quaisquer alterações e nem a presença de colônias bacterianas.

O fio polipropileno deslizou facilmente pelas paredes da artéria receptora e dos implantes, sem apresentar qualquer resistência. A maior dificuldade ocorreu no momento da execução dos nós, uma vez que o polipropileno possui "memória" e seu movimento levou os nós a se desfazerem, dificultando a manipulação. Tal característica exigiu maior destreza na execução dos pontos nas anastomoses.

A cateterização das artérias ilíacas externas permitiu a execução da angiografia contrastada com facilidade, sendo possível, dessa forma, a avaliação da patência do sítio de anastomoses, como também dos ramos regionais. A angiografia contrastada registrou respostas variadas do implante-receptor quanto aos diferentes tempos de avaliação.

De acordo com o teste estatístico $\chi^{2}$ em 5\% de significância, registrou-se diferença significativa quanto ao tempo de observação no grupo glicerinapolipropileno, sendo observada aos 60 dias de pós operatório, patência total em $25 \%$ dos animais do grupo, parcial em $50 \%$ e ausência de patência em $25 \%$. Já aos 120 dias foram observadas patência total em 50\% dos animais, parcial em $25 \%$ e ausência de patência nos outros $25 \%$.

No grupo sal-polipropileno foi observada diferença estatisticamente significativa, quanto ao tempo de observação, de acordo com o teste $\chi 2$ em $5 \%$ de significância, apresentando $50 \%$ de patência total e $50 \%$ de ausência de patência aos 60 dias, enquanto que aos 120 dias de pós operatório apresentou patência total em $25 \%$ dos animais, parcial em $25 \%$ e $50 \%$ de 
ausência de patência. Na Figura 1A, é possível observar o resultado presente no grupo sal-polipropileno, enquanto a Figura 1B demonstra o resultado do grupo glicerina-polipropileno. Os achados macroscópicos observados nas biópsias estão demonstradas nas Figuras $1 \mathrm{C}$ e $1 \mathrm{D}$.

$\mathrm{Na}$ microscopia do grupo com emprego da glicerina como meio de conservação, foram observadas aos 60 dias: anastomose com abundante tecido fibrovascular frouxo; infiltrado linfoplasmocitário discreto; reação ao fio de sutura; extensa fibrose entre as cartilagens da traquéia e hemorragia na parede. Aos 120 dias observou-se: integração com trombo organizado e espessamento da íntima na integração arterial.

No grupo com solução concentrada de cloreto de sódio, aos 60 dias foram observadas: integração mascarada por trombo organizado no local e aspecto semelhante entre cartilagem e traquéia. Enquanto que aos 120 dias constatou-se: anastomose com abundante tecido fibrovascular frouxo infiltrado por focos linfoplasmocitários; acúmulo de hemossiderina e reação granulomatosa aos fio de sutura.
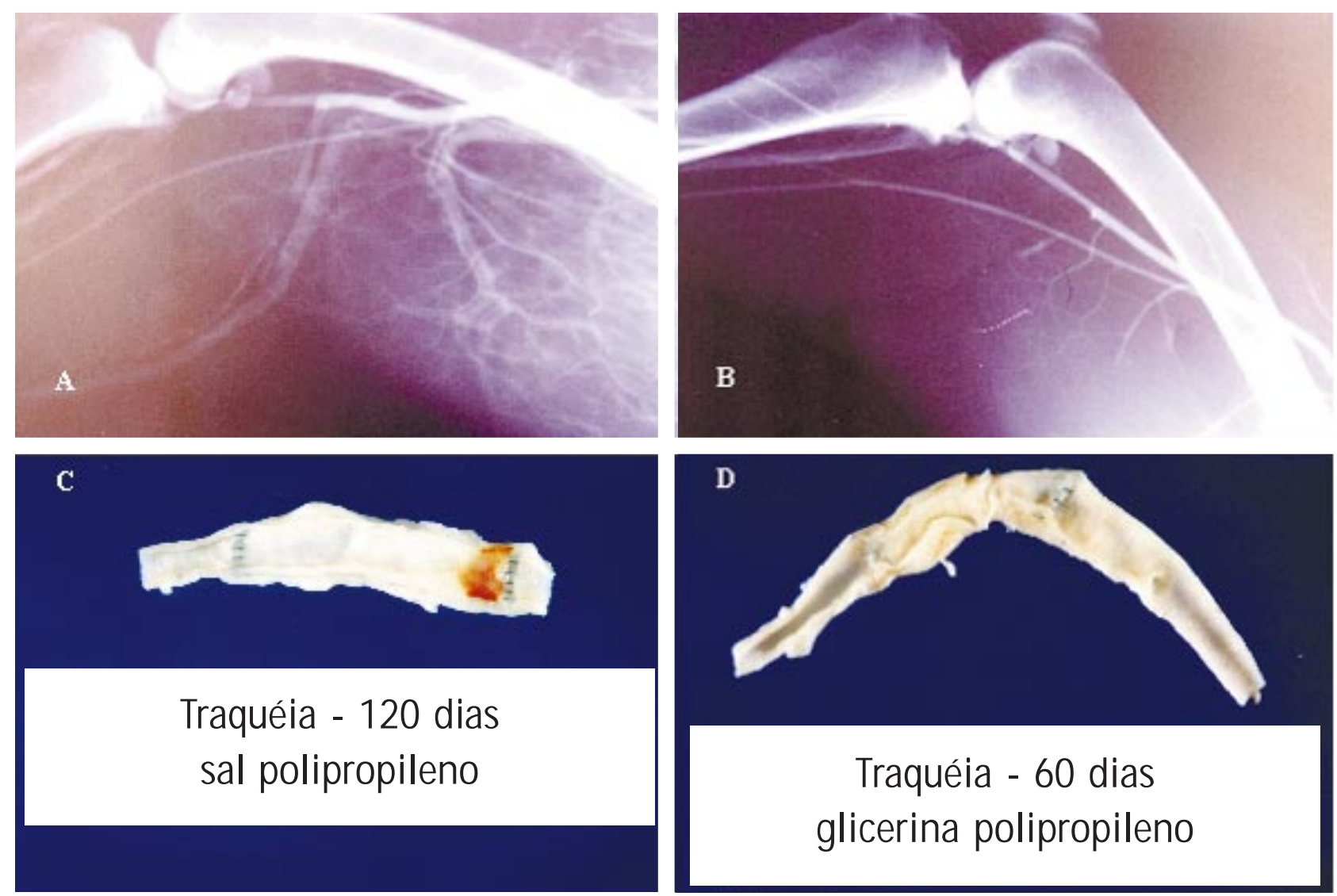

Figura 1. (A) Aspecto radiográfico de implante de traquéia conservado em solução concentrada de cloreto de sódio aos 60 dias de pós operatório, com patência total da artéria; (B) patência total de implante de traquéia conservado em glicerina a 98\% aos 120 dias de pós operatório. (C) Aspecto macroscópico de implante traqueal conservado em solução concentrada de cloreto de sódio aos 120 dias com discreto derrame sangüíneo impregnado na parede do vaso e (D) é evidenciada a diminuição da luz do vaso no local do implante aos 60 dias de pós operatório.

\section{DISCUSSÃO}

O uso de solução heparinizada, tanto nos implantes quanto no lume das extremidades arteriais receptoras seccionadas, permitiu a completa remoção do sangue, prevenindo também a formação de coágulos, os grandes responsáveis por episódios de obstrução nas microcirurgias vasculares [26]. A ação espasmolítica da lidocaína foi benéfica, impedindo a retração longitudinal e circunferencial naturais de uma artéria com a parede lesionada [10]. O enxerto venoso apresenta algumas limitações como freqüentes falhas técnicas na escolha e na anastomose ou devido à flebites. A prótese de politetrafluoetileno [17,28], a artéria carótida de coe- 
lhos conservada em glutaraldeído [22] e a carótida homógena conservada em glicerina foram implantadas em substituição de segmento arterial com resultados promissores [21]. A traquéia de Gallus domesticus, apresenta características básicas que justificam seu uso como substituto segmentar arterial: a conformação anatômica cilíndrica, com anéis sobrepostos, a disponibilidade de diâmetros variados, de acordo com a idade do doador, e o longo comprimento, que com pequena variação de idade fornece biomaterial com o diâmetro necessário para as artérias receptoras [13].

A anastomose vascular término-terminal é considerada a mais simples, amplamente difundida e facilmente exeqüível, permitindo eficiente fluxo sangüíneo de uma extremidade à outra [10]. Quanto ao padrão de sutura da anastomose simples interrompido é indicado que seja realizado a partir de dois pontos de reparo, intercalado por um em cada quadrante [14,29], sendo ideal a distribuição de oito pontos de sutura na circunferência da microanastomose arterial [5]. A grande vantagem do emprego da sutura simples interrompida é a dela não limitar o desenvolvimento do vaso sangüíneo em animais em fase de crescimento [15]. A facilidade na síntese da anastomose pode ser atribuída, em parte, ao emprego dos pontos de reparo. Dispostos em $180^{\circ}$, eles possibilitam a sutura da parede posterior mediante um giro, também de $180^{\circ}$, ao mesmo tempo em que permitem ao cirurgião não incluir a parede posterior na sutura do primeiro plano. Tal manobra impede a transfixação de parede, episódio desastroso para a anastomose $[12,26]$.

A resposta dos tecidos ao fio de sutura varia de acordo com o fio e em relação à natureza do próprio tecido [1]. O fio ideal, além de fácil manuseio, precisa ser resistente, não embologênico, imunologicamente inerte, não cancerígeno e, após cumprir sua função, deve desaparecer totalmente, não vindo a constituir-se em corpo estranho e permitindo o crescimento dos vasos. Os fios inabsorvíveis não possuem estas duas últimas características. Para possibilitar o crescimento dos vasos é necessário utilizar determinados artifícios técnicos, como o do padrão de sutura interrompida [8]. A grande vantagem dos polímeros sintéticos, como o polipropileno e a poliamida, é a de sua baixa antigenicidade - eles se caracterizam por uma mínima reação inflamatória, como também a de sua força tensora na anastomose [15]. O emprego de fio polipropileno revelou-se igualmente adequado, con- firmado as qualidades sugeridas na literatura consultada [5,11,25], mesmo considerando a relativa dificuldade na execução dos nós na anastomose.

A profilaxia antibacteriana mostrou-se eficaz, uma vez que nenhum dos animais apresentou sinais sugestivos de contaminação. Mas a ausência de contaminação local não se deveu apenas ao tratamento profilático antibacteriano pré-operatório, é preciso reconhecer também o papel do protocolo utilizado na reidratação dos implantes [21].

A técnica de criopreservação tem sido citada desde o início do século XX por Carrel e novamente testada na conservação de vasos sangüíneos no final deste mesmo século [19,4]. O glutaraldeído foi utilizado pela primeira vez por Carpentier em 1968 e posteriormente foi utilizado para reduzir a antigenicidade de vasos sangüíneos [22]. A glicerina é utilizada como conservante de material biológico desde estudos da década de 1960 [20]. É considerada como um conservante com ação anti-séptica, embora limitada em relação às bactérias esporuladas; possui propriedades viricidas e bactericidas $[9,27]$, sendo considerada um dos meios mais utilizados, tanto experimentalmente quanto em casos clínicos [7]. A solução hipersaturada de cloreto de sódio tem sido objeto de pesquisas como conservante de material biológico nos últimos anos. Ensaios cirúrgicos foram realizados com o objetivo de testar a viabilidade da solução salina na proporção de $1,5 \mathrm{~g}$ de sal comercial para $1 \mathrm{~mL}$ de água tridestilada $[2,3]$.

O meio de conservação dos biomateriais, glicerina a $98 \%$ e solução concentrada de cloreto de sódio, influiram positivamente na qualidade dos resultados, apresentando características adequadas como conservante. Submetidos aos testes microbiológicos para detecção de bactérias, ambos os meios apresentaram-se dentro do protocolo estabelecido, sem a presença de colônias bacterianas [3,9,27]

A solução de contraste à base de amidotrizoato de sódio e amidotrizoato de meglumina apresentou difusão intra-arterial e contraste adequados, permitindo que a artéria avaliada, assim como as neovascularizadas e suas ramificações, fossem facilmente identificadas $[6,30]$.

A heterogeneidade dos resultados revelou-se nos diversos tipos de avaliação. A mensuração da pulsação distal da artéria femoral relaciona-se à variação dos resultados da avaliação macroscópica, da angiográfica e da microscópica [16]. 
A variação nos resultados da implantação da traquéia pode indicar a necessidade de uma amostragem mais abrangente para maior detalhamento estatístico. É importante ressaltar, inobstante, que os índices de patência são compatíveis aos assinalados nos trabalhos consultados[4,23,28].

A avaliação macroscópica apresenta a mesma variedade de resultados observada na angiográfica, com trombos diminuindo ou obliterando a luz vascular e o espessamento da parede, o que pode ter interferido na patência arterial [23].

No que se refere à microscopia, a proliferação de tecido fibrovascular entre o implante e a artéria sugere uma interação entre eles [24,28].

A antigenicidade conferida aos biomateriais pelos meios de conservação $[2,3,20]$, foi confirmada pela ausência de reação de rejeição.

Uma pequena reação granulomatosa em torno dos fios de sutura indica que eles não interferiram no processo cicatricial da anastomose, corroborando a literatura consultada [17].

\section{CONCLUSÃO}

Ambos os meios de conservação, glicerina a 98\% e solução concentrada de cloreto de sódio foram meios adequados para conservação da traquéia de Gallus domesticus, visando sua utilização como implante em cães; a manutenção da patência está estatisticamente relacionada com o tempo de observação do implante e que novos estudos devem ser realizados com o objetivo de caracterizar a influência de cada variável em um maior número de unidades experimentais, a fim de tornar a microcirurgia parte do cotidiano clínico-cirúrgico veterinário.

Agradecimento: Os autores agradecem à professora Dra. Andrea Pinto Loguercio pelo auxílio na interpretação da análise estatística dos resultados.

\section{REFERÊNCIAS}

1 Actis-Dato G.M., Persiani M. \& Bassano C. 1994 Sutura estetica degli arti inferiori dopo prelievo della vena safena in cardiochirurgia: polildiossanone vs vicryl. Minerva Cardiolangiologica. 42: 477-481.

2 Brun M.V., Pippi N.L, Dreimeier D., Contesini E.A., Beck C.A.C., Cunha O., Pinto Filho S.L., Roehsig C. \& Stedile R. 2002. Solução hipersaturada de sal como conservante de pericárdio canino utilizado na reparação do músculo reto abdominal de ratos Wistar. Ciência Rural. 32: 1019-1025.

3 Brun M.V., Pippi N.L, Dreimeier D., Contesini E.A., Beck C.A.C., Cunha O., Pinto Filho S.L., Roehsig C., Stedile R. \& Silva T.F. 2004. Solução hipersaturada de sal ou glicerina a $98 \%$ como conservantes de centro frênico canino utilizado na reparação de defeitos musculares em ratos Wistar. Ciência Rural. 34: 147-153.

4 Cavadas P.C. \& Vera-Sempere F.J. 1996. In vivo microarterial freezing: experimental study. Microsurgery. 17: 109-114.

5 Chen L.E., Seaber A.V. \& Urbaniak J.A. 1993. Comparison of 10-0 polypropylene and 10-0 nylon sutures in rat arterial anastomosis. Microsurgery. 14: 328-333.

6 Chen Y.X., Chen L.E. \& Seaber A.V. 2001. Comparison of continuous and interrupted suture techniques in microvascular anastomosis. The Journal of Hand Surgery. 26: 530-539.

7 Contesini E.A., Salles M.S. \& Pigatto J.A.T. 2001. Reparação traqueal em cães: transplante autógeno vs implante homógeno conservado em glicerina a 98\% de cartilagem da pina. Ciência Rural. 31: 633-637.

8 Cooley D. \& Wukasch D.C. 1979 Techniques in vascular surgery. Philadelphia: Saunders, 168p.

9 De Backere A.C.J. 1994. Euro skin bank: large scale skin-banking in Europe based on glycerol-preservation of donor skin. Burns. 20 (Suppl 1): S4-S9.

10 De La Peña-Salcedo J.A., Cuesy C. \& López-Monjardin H. 2000. Experimental microvascular sleeve anastomosis in size discrepancy vessels. Microsurgery. 20: 173-175.

11 Delriviere L., Kamada N. \& Goto S. 1993. Replantation of the liver in the rat. Microsurgery. 14: 416-419.

12 Friedrick R.E., Bartel-Friedrick S. \& Plambeck K. 2000. The presence of collagen III and IV in experimental microsurgical anastomoses of arteries. Journal of Oral and Maxillofacial Surgery. 58: 1125-1128. 
13 Ghoshal N.G. 1981. Coração e artérias do carnívoro. In: Getty R. (Ed). Anatomia dos animais domésticos. 5.ed. Rio de Janeiro: Interamericana, pp.1497-1550.

14 Hui K., Zhang F. \& Shaw W. 2002. Assessment of the patency of microvascular venous anastomosis. Journal of Reconstructive Microsurgery.18: 111-114.

15 Kallás I.E., Kallás A.C. \& Kallás E. 1999. Anastomoses arteriais: passado, presente e futuro. Acta Cirúrgica Brasileira. 14: Disponível em: 〈http://www.scielo.br〉. Acesso em: 31 maio 2002.

16 Kallás I.E., Souza V.C.T. \& Gomes P.O. 1998. Estudo comparativo das anastomoses arteriais com fio absorvível e nãoabsorvível em suínos em crescimento. Acta Cirúrgica Brasileira. 13: Disponível em: <http://www.scielo.br>. Acesso em: 31 maio 2002.

17 Kruavit A., Fletcher C.D.M. \& Mckee P.H. 1987. Experimental microvascular autogenous vein grafts for arterial defects: a study of anastomotic sites. Microsurgery. 8: 201-207.

18 Litwak P. 1993. Principles of vascular surgery. In: Slatter D.H. (Ed). Textbook of small animal surgery. 2nd edn. Philadelphia: Saunders, pp.890-893.

19 Mesa F., Serra J.M. \& Herreros J. 1997. Vascular cryopreservation in microsurgery. Journal of Reconstructive Microsurgery. 13: 245-250.

20 Pigossi N. 1967. Glicerina na conservação de dura-máter - estudo experimental. 36 f. São Paulo, SP: Tese (Livre Docência) - Faculdade de Medicina, Universidade de São Paulo.

21 Raiser A.G., Pippi N.L. \& Graça D.L. 2000. Implantação de homoenxerto heterotópico na artéria femoral de cães. Arquivo Brasileiro de Medicina Veterinária e Zootecnia. 52: 222-229.

22 Roberts A.H.N., Wee J.T.K. \& Nightingale G. 1989. Glutaraldehyde-tanned microvascular grafts. British Journal of Plastic Surgery. 42: 429-434.

23 Sanders J.E., Malcolm S.D. \& Bale Y.N. 2002. Prevascularization of biomaterial using a chorioallontoic membrane. Microvascular Research. 64: 174-178.

24 Shoen F.J. 1994. Blood vessels. In: Cotran R.S., Kumar V. \& Robbins S.L.(Eds). Pathologic basis of disease. 5 th edn. Philadelphia: Saunders, pp.467-516.

25 Steinbecker K.M., Teague J.L. \& Wiltfong D.B. 1999. Testicular histology after transparenchymal fixation using polytetrafluoethylene suture: an animal model. Journal of Pediatric Surgery. 34: 1822-1825.

26 Turan T., Ozcelik D. \& Kuran I. 2001. Eversion with four sutures: an easy, fast, and reliable technique for microvascular anastomosis. Plastic and Reconstructive Surgery. 107: 463-470.

27 Van Baare J., Buitenwerf J. \& Hoekstra M.J. 1994. Virucidal effect of glycerol as used in donor skin preservation. Burns. 20(Suppl 1): 77-80.

28 Veselý J., Bravo C. \& Samohýl J. 2000. A survey of different successful microsurgical vascular prostheses in animal experiments. Acta Chirurgiae Plasticae. 42: 43-45.

29 Yoshida W.B., Naresse L.E. \& Rodrigues A.C. 2002. End-to end arterial anastomosis with fibrin glue in larger arteries: histology, hydroxyproline concentration and tensile strength study in carotids of rabbits. Acta Cirúrgica Brasileira.17: $1-7$.

30 Zhang L., Moskovitz M. \& Baron D. 1995. Different types of sleeve anastomosis. Journal of Reconstructive Microsurgery. 11: 461-465. 